ELKOM, Vol.11, No.2, Desember 2018, pp. 1 - 15

p-ISSN : 1907-0012 (print)

e-ISSN : 2714-5417 (online)

http://ejurnal.stekom.ac.id/index.php/home

- page 1

\title{
SISTEM INFORMASI PEMESANAN BERBASIS WEB PADA PT. VERMINDO UTAMA SEMARANG
}

\author{
Siswanto Siswanto \\ ${ }^{1}$ Progdi Sistem Komputer - Sekolah Tinggi Elektronika dan Komputer (STEKOM), \\ siswanto@stekom.ac.id \\ Jl. Majapahit 605, Semarang, telp/fax : (024) 6723456
}

\begin{tabular}{l}
\hline ARTICLE INFO \\
\hline Article history: \\
Received 19 November 2018 \\
Received in revised form 23 Nov 2018 \\
Accepted 25 Nov 2018 \\
Available online 13 Desember 2018
\end{tabular}

\begin{abstract}
PT. Vermindo Utama Semarang having its address at $\mathrm{Jl}$. Pawiyatan Luhur Number 25 Semarang is a company engaged in the distribution and production of goods, especially health products. PT. Vermindo Utama Semarang has dozens of Salesmen and a leader. PT. Vermindo Utama Semarang carries out the process of buying and selling wholesale with various customers, the majority of whom are Pharmacies and supermarkets. In running its business, PT. Vermindo Utama Semarang still sells conventionally by using salesmen. And the marketing area still covers Central Java and East Java. Based on the problems above, the writer wants to propose a webbased booking system design to be considered in helping in the promotion of goods from PT. Vermindo Utama Semarang. Application Order System PT. Vermindo Utama Semarang by using PHP and MySql database. Making this application is expected to be one of the efforts that can be done to overcome the problems that often occur so as to increase the effectiveness of work which will certainly affect the quality of service to customers.
\end{abstract}

Keywords: System, Ordering, Goods, Website.

\section{Pendahuluan}

Banyak sekali potensi pemasaran melalui media internet yang dapat di gali. Internet merupakan sebuah media yang memungkinkan seseorang dapat saling berkomunikasi multi arah, baik berbasiskan teks, suara, gambar, bahkan video. Seiring perkembangan internet yang semakin pesat, internet kini telah banyak membantu pekerjaan manusia mulai hanya sekedar berkirim pesan, informasi sampai dengan hiburan. Bahkan kini internet digunakan untuk memasarkan produk dan jasa.

Dengan meningkatnya jumlah pengguna internet setiap hari tentunya akan memperbesar potensi pemasaran melalui internet. Tak heran jika sekarang banyak pengusaha online yang memanfaatkan website, email, jejaring sosial, video sharing dan lain sebagainya untuk menawarkan produk dan jasa di internet.

PT. Vermindo Utama yang beralamatkan di Jl. Pawiyatan Luhur No: 25 Bendan Dhuwur Semarang adalah sebuah perusahaan yang bergerak di bidang usaha produksi dan distribusi. Produk yang dihasilkan adalah susu kedelai dengan merk ProPLUS. Selain ProPLUS, PT Vermindo Utama juga menjadi distributor produk-produk yang dihasilkan PT Vermindo Internasional, utamanya adalah produk dengan merk Vermint.

Secara umum dalam menjalankan pola distribusi dan promosi PT Vermindo Utama masih secara konvensional, yaitu dengan menggunakan tenaga salesman yang secara langsung datang kepada pelanggan. Pelanggan PT. Vermindo Utama adalah Apotek, toko obat dan supermarket, contohnya saja Received Nov 19, 2018; Revised Nov 23, 2018; Accepted Nov 25, 2018 
di Semarang dimana terdapat beberapa tenaga salesman lokal yang bertugas terhadap penjualan di area pemasaran tersebut. Wilayah pemasaran PT Vermindo Utama pada saat ini baru mencakup wilayah Jawa Tengah dan Jawa Timur, sementara daerah lain belum ada. PT. Vermindo Utama juga berkeinginan untuk melayani pesanan barang ke luar pulau Jawa dalam jumlah yang besar. Sementara informasi tentang perusahaan di luar pulau Jawa belum ada. Hal ini menjadi kendala untuk mengembangkan perusahaan menjadi lebih maju.

Berikut ini adalah data pelanggan PT. Vermindo Utama Semarang.

Tabel.1 Gambaran data pelanggan PT. Vermindo Utama Tahun 2010

\begin{tabular}{|c|c|c|c|c|c|c|c|c|c|}
\hline \multirow{2}{*}{ Produk } & \multicolumn{3}{|c|}{ Jawa Tengah } & \multicolumn{3}{c|}{ Jawa Timur } & \multicolumn{3}{c|}{ Area Lain } \\
\cline { 2 - 10 } & Apotik & $\begin{array}{c}\text { Super } \\
\text { market }\end{array}$ & $\begin{array}{c}\text { Toko } \\
\text { obat }\end{array}$ & Apotik & $\begin{array}{c}\text { Super } \\
\text { market }\end{array}$ & $\begin{array}{c}\text { Toko } \\
\text { obat }\end{array}$ & Apotik & $\begin{array}{c}\text { Super } \\
\text { market }\end{array}$ & $\begin{array}{c}\text { Toko } \\
\text { obat }\end{array}$ \\
\hline $\begin{array}{c}\text { Vermint isi } \\
16\end{array}$ & 214 & - & 78 & 134 & - & 46 & - & - & - \\
\hline $\begin{array}{c}\text { Vermint isi } \\
30\end{array}$ & 214 & - & 78 & 134 & - & 46 & - & - & - \\
\hline $\begin{array}{c}\text { Susu Pro Plus } \\
\text { Kuning }\end{array}$ & - & 4 & 56 & - & 3 & 34 & - & - & - \\
\hline $\begin{array}{c}\text { Susu Pro Plus } \\
\text { Biru }\end{array}$ & - & 4 & 56 & - & 3 & 34 & - & - & - \\
\hline
\end{tabular}

Pesaing di bidang produk ProPLUS ataupun Vermint cukup banyak. Antara lain merk MDL 525, Malilea, Tilung, Vermino, dan Vermipro, serta beberapa produk lain. Sedangkan model promosi yang dilakukan masih berupa penyebaran brosur di pelanggan-pelanggan, serta pemasangan spanduk dan iklan di radio-radio setempat.

Melihat besarnya cakupan wilayah, serta minimnya tenaga salesman yang ada maupun metode promosi yang dilakukan, serta pasar dan pesaing yang semakin tumbuh. Penulis berpendapat PT Vermindo Utama memerlukan perubahan ataupun peningkatan strategi dalam menyikapi perkembangan pasar. Melihat perkembangan teknologi informasi yang semakin pesat dan semakin canggih, penulis mencoba menawarkan sebuah konsep pemasaran secara online, yaitu dengan membuat sebuah sistem berbasis web yang berfungsi sebagai media promosi, perluasan area pemasaran, sekaligus transaksi secara online. Maka Judul yang akan diteliti adalah: "SISTEM INFORMASI PEMESANAN BARANG BERBASIS WEB PADA PT. VERMINDO UTAMA SEMARANG”.

\section{Landasan Teori \\ Pengertian Sistem}

Sistem adalah sehimpunan unsur yang melakukan sesuatu kegiatan atau menyusun skema atau tata cara melakukan sesuatu kegiatan pemrosesan untuk mencapai sesuatu atau beberapa tujuan, hal ini dilakukan dengan cara mengolah data dan atau energi dan atau barang (benda) didalam jangka waktu tertentu guna menghasilkan informasi dan atau energi dan atau barang. (Jogiyanto, 2005)

Pengertian Informasi

Dalam manajemen, informasi merupakan data yang telah diproses sehingga mempunyai arti tertentu bagi penerimanya. Sumber dari informasi adalah Data, sedangkan Data itu sendiri adalah Kenyataan yang menggambarkanm suatu kejadian, sedangkan kejadian itu merupakan suatu peristiwa yang terjadi pada waktu tertentu .dalam hal ini informasi dan data saling berkaitan.

Informasi adalah data yang diolah menjadi bentuk yang lebih berguna dan lebih berarti bagi yang menerimanya. (Jogiyanto, 2005).

\section{Pengertian Sistem Informasi}

Menurut Hartono (2005) Sistem informasi dapat didefinisikan sebagai suatu sistem di dalam suatu organisasi yang merupakan kombinasi dari orang - orang, fasilitas, teknologi, media, prosedur - prosedur dan pengendalian yang ditujukan untuk mendapatkan jalur komunikasi penting, memproses tipe transaksi rutin tertentu, memberi sinyal kepada manajemen dan yang lainnya terhadap kejadian - kejadian internal dan eksternal yang penting dan menyediakan suatu dasar informasi untuk pengambilan keputusan yang cerdik.

ELKOM Vol. 11, No. 2, Desember 2018: 1-15 
Menurut Raymond Mcleod (2008) Sistem informasi adalah sebuah rangkaian prosedur formal dimana data dikelompokkan, diproses, menyimpan, menganalisis, dan menyebarkan informasi untuk tujuan yang spesifik. Sistem informasi adalah kerangka kerja yang mengkoordinasikan sumber daya (manusia, komputer) untuk mengubah masukan (input) menjadi keluaran (informasi), guna mencapai sasaran-sasaran perusahaan.

Informasi adalah data yang telah diolah dan dianalisa secara formal dengan cara yang benar dan secara efektif, sehingga hasilnya bisa bermanfaat dalam operasi manajemen. Informasi yang akan dibuat oleh penulis menggunakan sistem desain web.

\section{Pengertian SDLC}

Pendekatan yang dilakukan adalah SDLC (System Development Life Cycle). SDLC adalah suatu penerapan pendekatan sistem terhadap masalah pengenbangan sistem dan memiliki seluruh unsur-unsur pendekatan sistem dasar, diawali dengan identifikasi masalah dan diakhiri dengan penggunaan sistem. (Raymond, Mcleod, Jr, 2008).

\section{Metodologi}

Metode pengumpulan data merupakan salah satu faktor penting dalam suatu proses penyusunan skripsi dan juga merupakan suatu cara dalam mengembangkan serta menguji kebenaran dari suatu ilmu pengetahuan.

Metode yang digunakan dalam penulisan penelitian ini antara lain:

1. Objek Penelitian

Penulis memfokuskan penelitian tentang perpustakaan pada Perpustakaan SMA Negeri 1 Mranggen Demak, dengan meneliti sistem yang ada untuk kemudian mencoba merancang untuk mengembangkan menjadi sistem baru yang dianggap sesuai dengan keadaan Perpustakaan SMA Negeri 1 Mranggen Demak.

2. Jenis dan Sumber Data

Metode pengumpulan data yang digunakan dalam penyusunan meliputi dua jenis data yaitu :

\section{a. $\quad$ Data Primer}

Data primer adalah data-data yang diperoleh secara langsung dari tangan pertama atau sumber data itu sendiri di Perpustakaan SMA Negeri 1 Mranggen Demak. Pelaksanaan pengumpulan data primer ini dilaksanakan dengan cara sebagai berikut :

(1) Wawancara

Wawancara adalah mengadakan tanya jawab secara langsung kepada koresponden atau sumber data yang dalam hal ini diwakili oleh bagian Perpustakaan SMA Negeri 1 Mranggen Demak, yaitu mengenai hal-hal yang menjadi obyek penelitian dari laporan ini, sehingga segala sesuatunya dapat diketahui dengan jelas.

(2) Observasi

Observasi adalah mengadakan pengamatan secara langsung pada Perpustakaan SMA Negeri 1 Mranggen Demak yang bersangkutan, terutama sekali dengan hal-hal yang erat kaitannya dengan masalah perpustakaan yang akan dibuat sehingga akan diperoleh gambaran yang jelas.

(3) Penelusuran Literatur

Cara pengumpulan data dengan menggunakan sebagian atau seluruh data yang telah ada atau laporan data dari peneliti sebelumnya.

(4) Questionair

Cara pengumpulan data dengan menggunakan daftar pertanyaan terhadap objek yang diteliti.

(5) Studi Kepustakaan

Metode pengumpulan data dengan cara melakukan pencarian data pendukung dari media elektronik, buku dan internet.

b. Data Sekunder

Data Sekunder adalah data-data yang diperoleh dalam bentuk sudah jadi, berupa publikasi atau data diperoleh dari obyek penelitian, tetapi masih mempunyai hubungan erat dengan masalah yang dibahas. Data sekunder dapat diperoleh dari perpustakaan, brosur, catatancatatan lain yang kiranya mempunyai hubungan dengan masalah yang dibahas.

3. Metode Pengumpulan Data

Metode pengumpulan data yang digunakan dalam penyusunan meliputi dua metode yaitu :

a. Metode pengumpulan data kualitatif 
Yaitu dengan menjelaskan permasalahan atau data-data yang diperoleh dan dikumpulkan dari hasil riset tanya jawab dengan pengelola Perpustakaan SMA Negeri 1 Mranggen Demak yang tidak dapat diukur dengan angka. Contoh : DFD, Kamus Data, ERD, Normalisasi, dan Flowchart.

b. Metode pengumpulan data kuantitatif

Yaitu analisa data yang diperoleh dengan menggunakan angka-angka dari hasil observasi atau pengukuran.

\section{4. $\quad$ Metode Analisis Data}

Siklus hidup sistem merupakan suatu metodologi dalam penerapan pendekatan sistem untuk tugas mengembangkan dan menggunakan sistem berbasis komputer.

Dari rumusan masalah diatas penulis menentukan metode pengembangan sistem menggunakan SDLC (system development life cycle) atau sistem siklus hidup yang dapat digambarkan sebagai berikut :

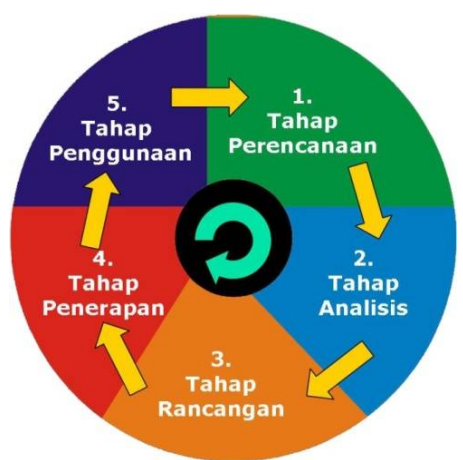

Gambar 1 Sistem Siklus Hidup

Adapun tahapan dalam sistem ini meliputi :

a. Tahap Perencanaan, yaitu tahap awal yang harus ditentukan dengan melakukan langkah langkah untuk menemukan suatu masalah, mendefinisikan masalah, menentukan tujuan, mengidentifikasikan kendala, membuat perencanaan operasional dan jadwal, serta mempersiapkan usulan penelitian sistem.

b. Tahap Analisis, yaitu penelitian atas sistem yang telah ada dengan tujuan untuk merancang sistem baru atau diperbaharui.

c. Tahap Rancangan, yaitu penentuan proses dan data yang diperlukan oleh sistem baru dan juga jenis peralatan yang akan digunakan. Dengan menyiapkan rancangan sistem yang terinci berupa rancangan terstruktur (diagram arus data) terdiri atas DFD, ERD, Database, Normalisasi dan rancangan tampilan input/output. Sehingga dapat mengidentifikasi serta mengevaluasi alternatif konfigurasi sistem untuk menghasilkan konfigurasi terbaik.

d. Tahap Penerapan, yaitu merupakan kegiatan memperoleh dan mengintegrasikan sumber daya fisik dan konseptual yang menghasilkan suatu sistem yang bekerja.

e. Tahap Penggunaan, yaitu merupakan kegiatan penggunaan sistem yang telah dibuat, mengevaluasi, memlihara serta menyiapkan usulan rekayasa ulang.

\subsection{Bahan Penelitian}

\section{Kebutuhan Sistem Data dan Informasi}

1. Identifikasi Sistem

Sistem yang dirancang saat ini adalah Sistem Informasi Pemesanan Barang Berbasis Web pada PT.

Vermindo Utama Semarang.

2. Identifikasi Data dan sumber data

a. Data Pelanggan

b. Data barang

c. Data kategori

3. Identifikasi Informasi dan tujuan informasi

a. Laporan pemesanan

b. Laporan pelanggan

c. Laporan Penjualan

ELKOM Vol. 11, No. 2, Desember 2018: 1-15 


\subsection{Desain Penelitian}

Sistem baru yang akan dikembangkan pada PT. Vermindo Utama Semarang dalam pengembangan didasarkan atas perolehan data dalam analisa sistem yang menyangkut beberapa aspek pada sistem lama. Berdasarkan hal terasebut sasaran sistem pemesanan meliputi :

1. Membuat sistem informasi pemesanan pada PT. Vermindo Utama Semarang diharapkan mampu menyelesaikan masalah yang ada pada sistem lama

2. Sistem Informasi yang dikembangkan diharapkan mampu menyajikan informasi yang lengkap dan lebih berdaya guna bagi perusahaan maupun pelanggan.

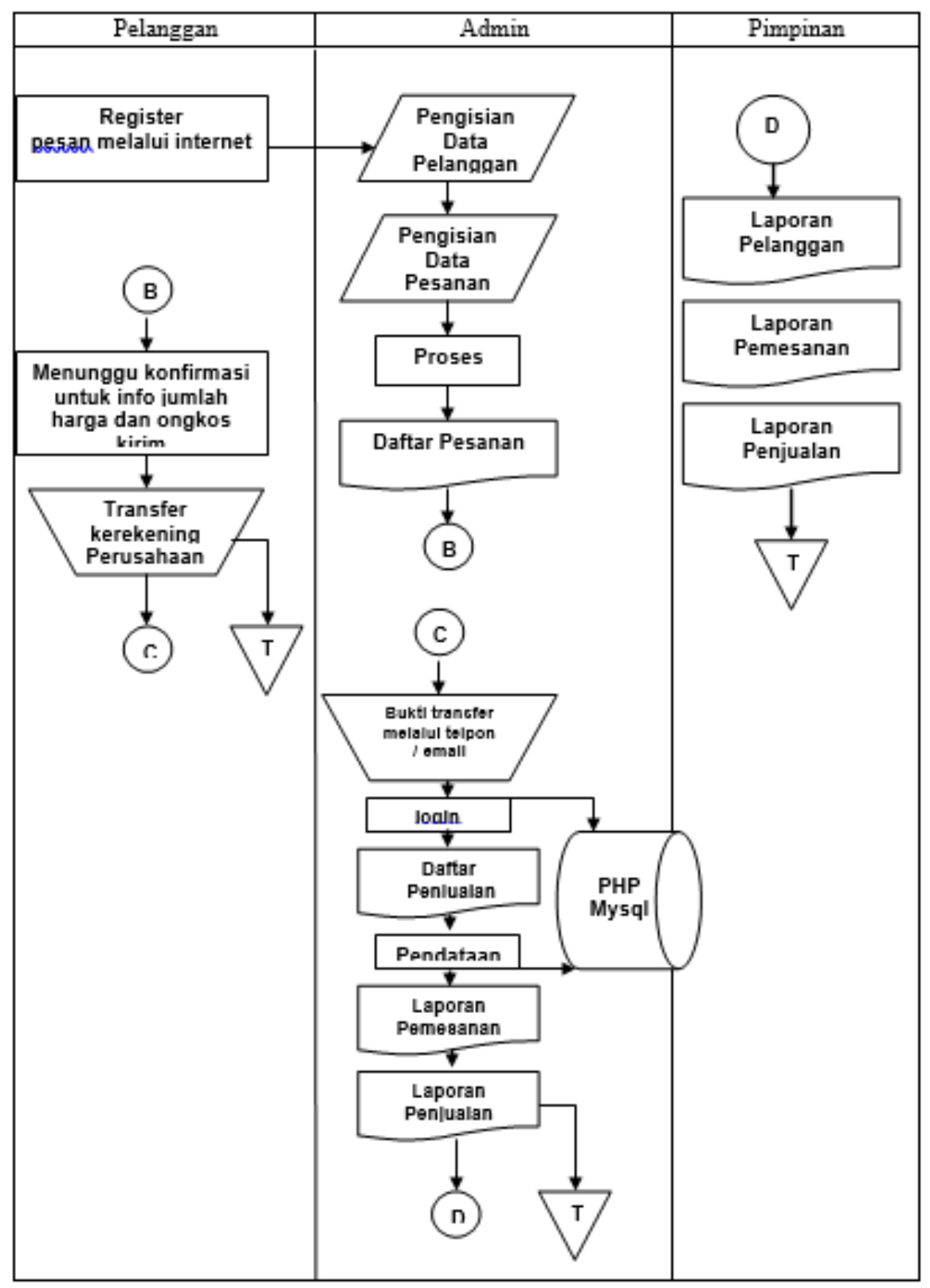

Gambar 2 Tabel Data Flow Baru

\subsection{Perancangan}




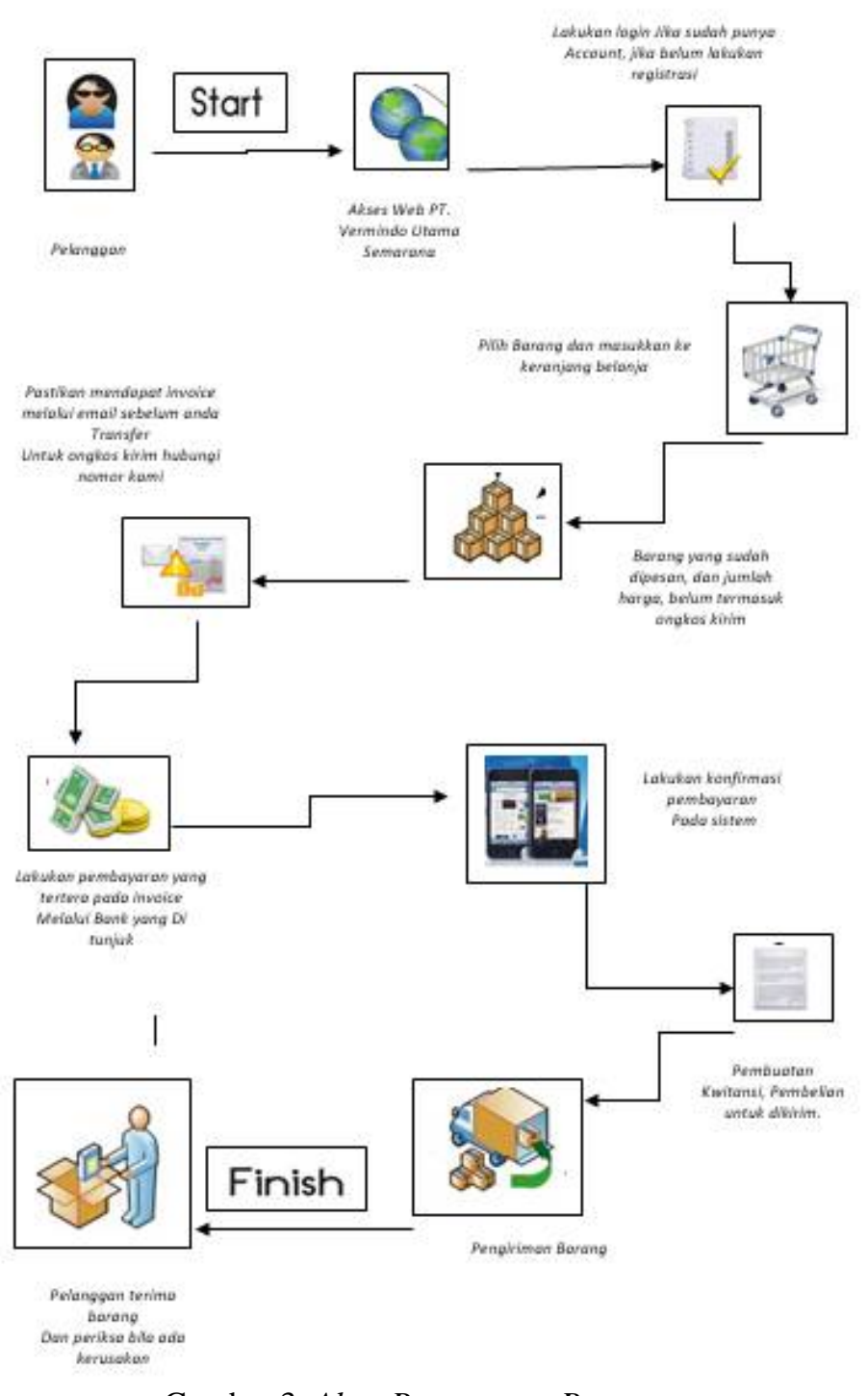

3.4 Narasi Sistem Baru

Gambar 3 Alur Pemesanan Baru

1.Pelanggan melakukan akses pada website PT. Vermindo Utama Semarang, pelanggan melakukan login jika sudah terdaftar. Jika belum mendaftar lakukan registrasi.

2. Pelanggan yang sudah masuk bisa melakukan belanja secara online dan bisa memesan barang yang diinginkan.

3. Pelanggan dapat mengetahui jumlah barang yang dipesan sekaligus harga yang akan dibayar.

4. Pastikan mendapat email sebelum anda transfer ke bank, untuk onkos kirim bisa konfirmasi ke Tiki melalui alamat yang telah disediakan.

5. Segera lakukan pembayaran jika telah sepakat dengan harga dan jumlah ongkos kirim. Ongkos kirim konfirmasi nomor kami.

6. Segara lakukan konfirmasi pembayaran via telpon atau email jika sudah mentrasfer uang pembayaran.

7. Perusahaan akan membuat kwitansi pembayaran untuk dikirim bersama barang yang telah dipesan.

8. Pengiriman barang dilakukan oleh Salesman dan jasa pengiriman tergantung pesanan barang dan jarak yang ditempuh.

9. Barang sampai ke pelanggan, jika rusak segera konfirmasi ke perusahaan.

\section{Hasil dan Pembahasan}

ELKOM Vol. 11, No. 2, Desember 2018: 1-15 
Hasil Perancangan

1. Tampilan Home

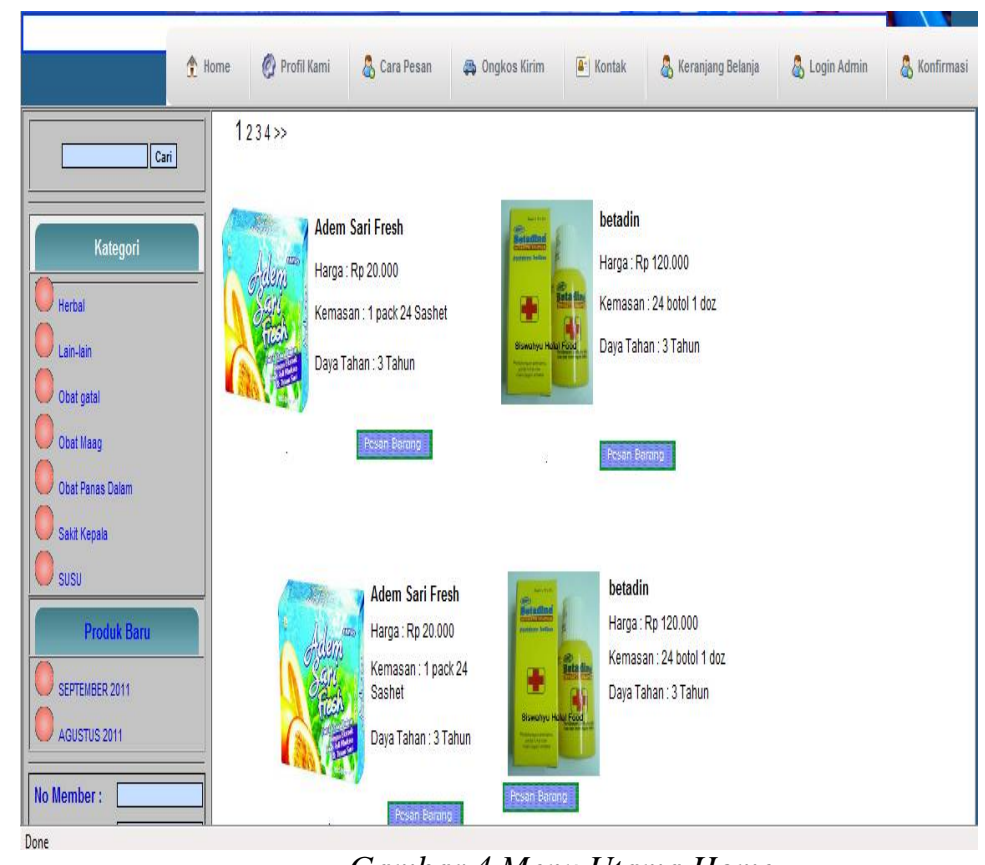

Gambar 4 Menu Utama Home

Keterangan :

Gambar diatas menunjukkan halaman home dimana terdapat informasi tentang kualitas barang dan pelayanan kepada pelanggan bahwa perusahaan vermindo unggul dalam bidangnya. Juga informasi pertanyaan dan informasi.

2. Tampilan Profil

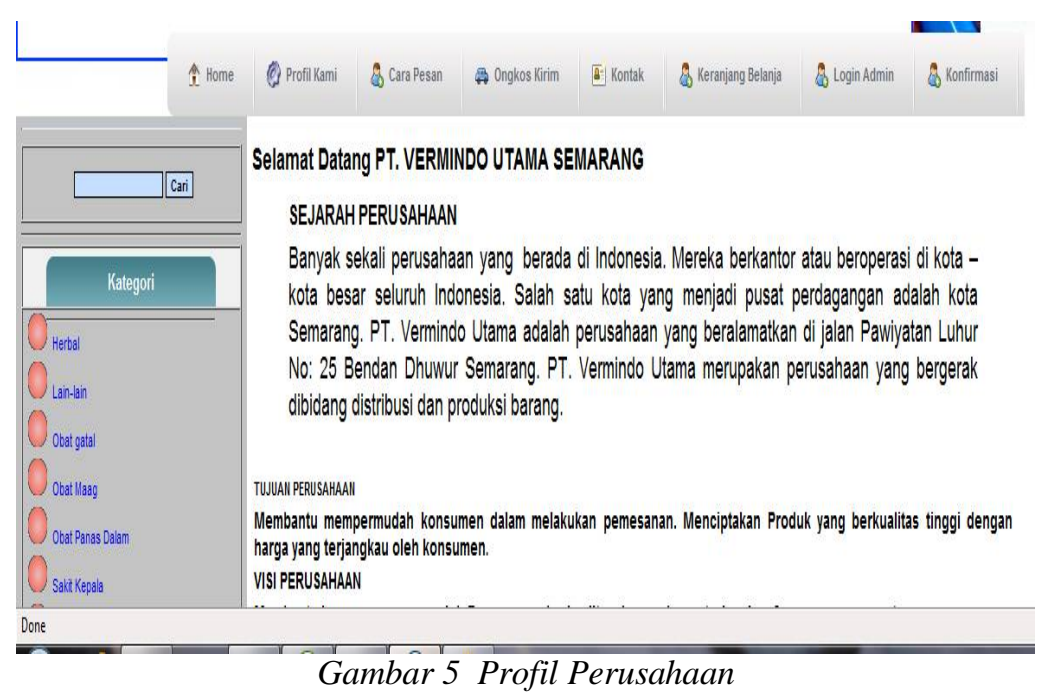

Keterangan :

Gambar diatas menunjukkan halaman profil dari PT. Vermindo Utama Semarang. Juga tujuan perusahaan kedepan serta visi dan misi perusahaaan.

3. Ongkos Kirim dan Pembayaran 


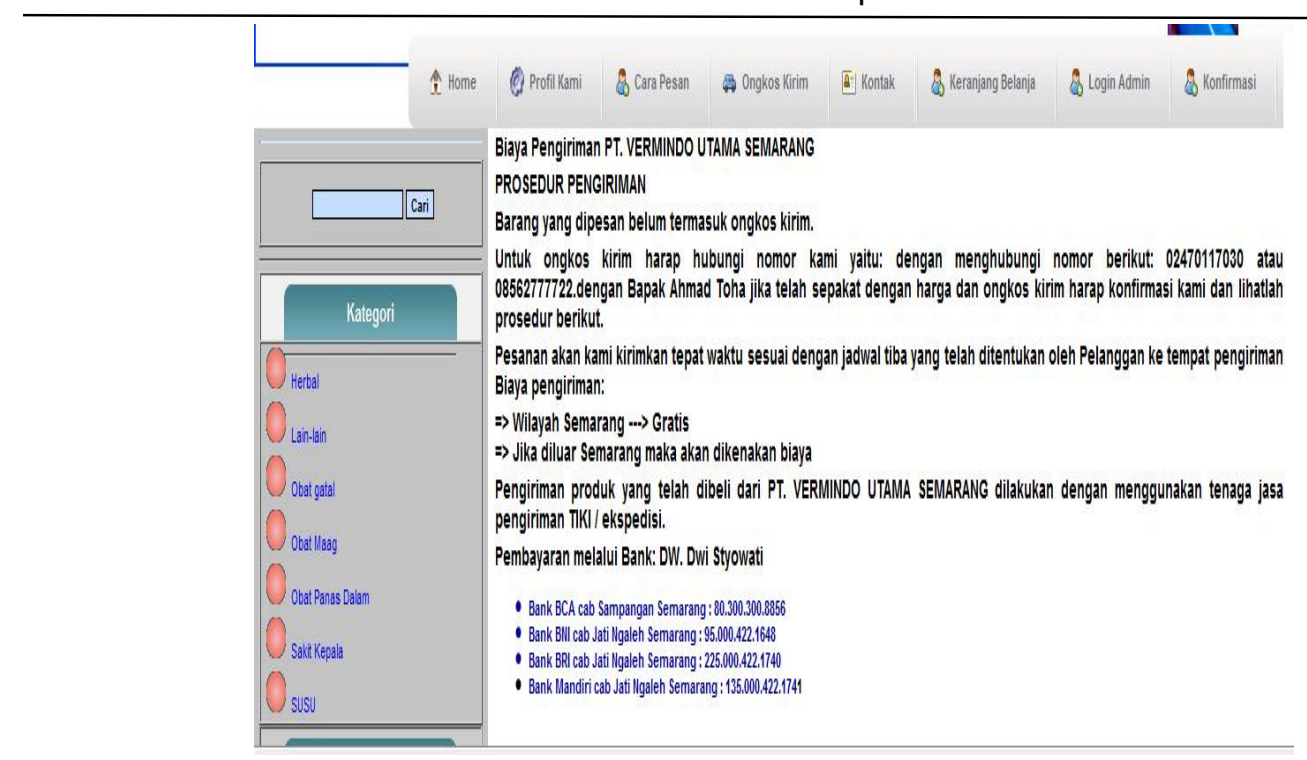

Gambar 6 Informasi Ongkos kirim

Keterangan :

Gambar diatas menunjukkan halaman konfirmasi ongkos kirim dan nomor rekening bank yang telah ditunjuk untuk melakukan pembayaran. Jadi pesanan belum termasuk ongkos kirim, harga ongkos kirim harap menghubungi informasi pada halaman ini.

4. Informasi Kontak

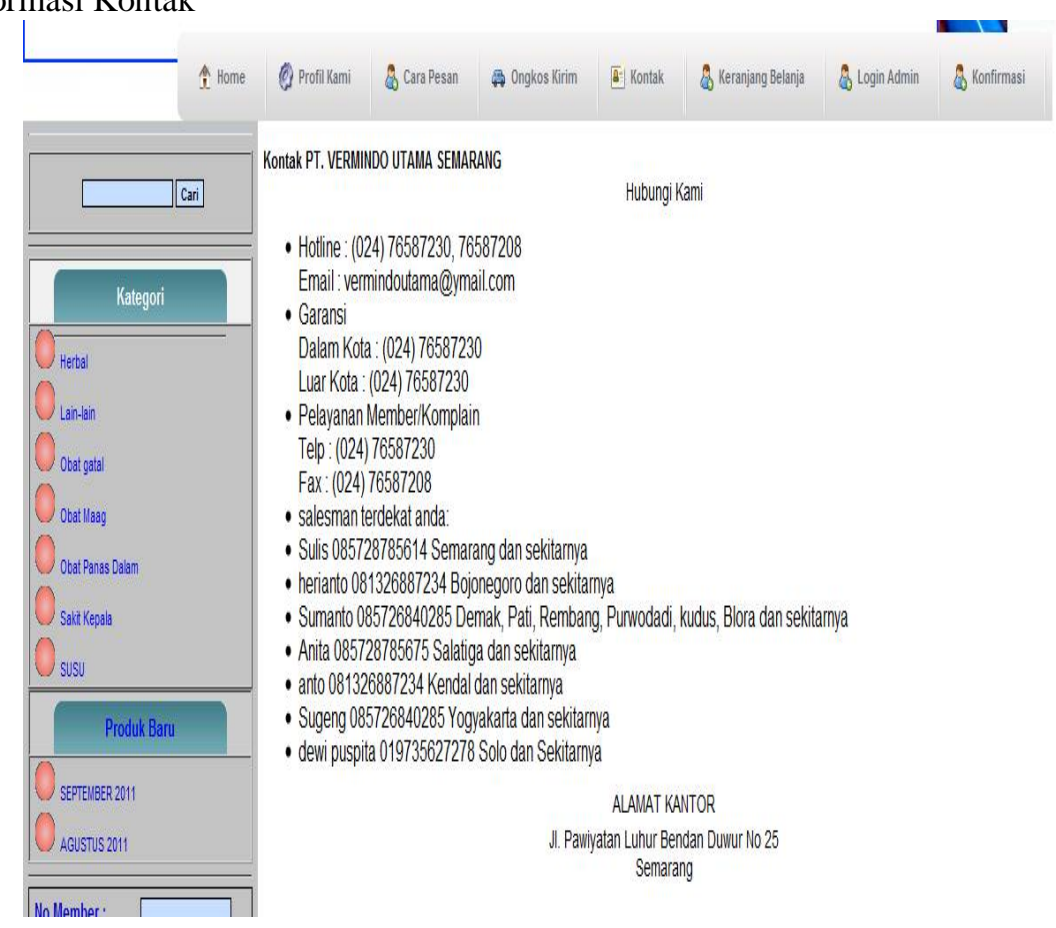

Gambar 7 Informasi Kontak

Keterangan :

Gambar diatas menunjukkan halaman kontak person dari PT. Vermindo Utama Semarang. Dimana terdapat informasi kontak salesman kami yang terdekat di kota anda.

ELKOM Vol. 11, No. 2, Desember 2018: 1-15 
5. Keranjang belanja

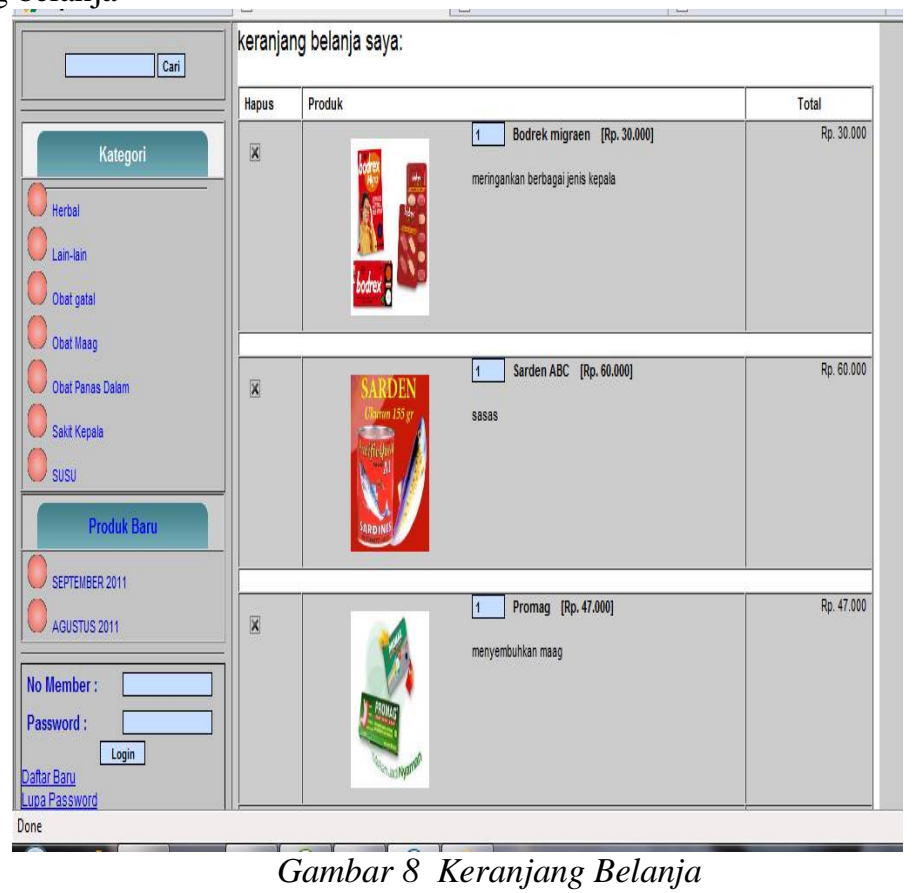

Keterangan :

Gambar diatas menunjukkan form halaman keranjang belanja PT. Vermindo Utama Semarang. Pelanggan dapat melihat daftar pesanan barang yang sudah dipesan dan menentukan berapa jumlah yang dipesan juga informasi tentang harga yang harus dibayar.

6. Informasi Pesan Barang

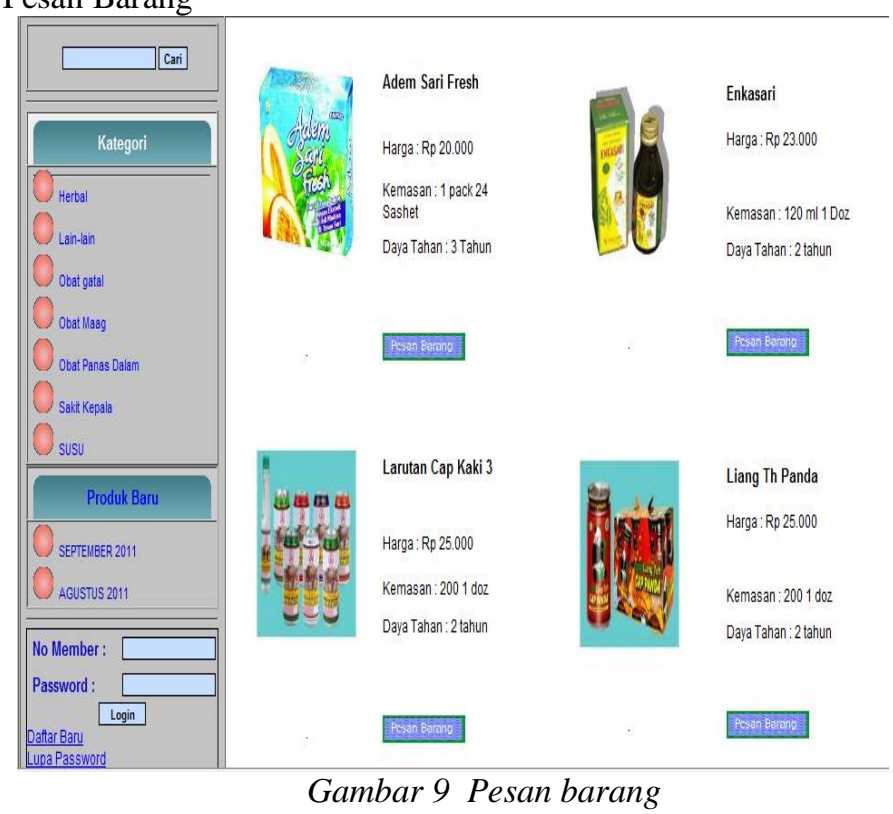

Keterangan :

Gambar diatas menunjukkan halaman pesan barang yang diakses oleh pelanggan. Pelanggan dapat memesan barang dengan menekan tombol pesan barang secara otomatis akan masuk kekeranjang belanja pelanggan. 
7. Barang Terbaru

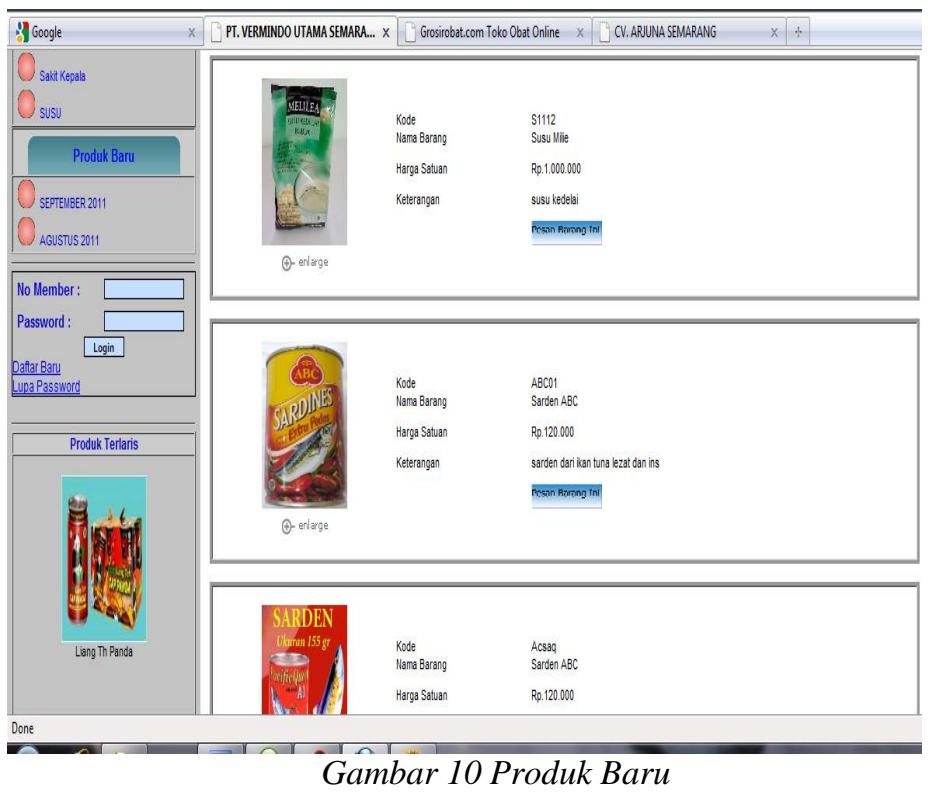

Keterangan :

Gambar diatas menunjukkan halaman barang terbaru dari PT. Vermindo Utama Semarang. Disini pelanggan dapat mengetahui informasi barang terbaru menurut bulan barang tersebut keluar.

8. Pendaftaran Pelanggan

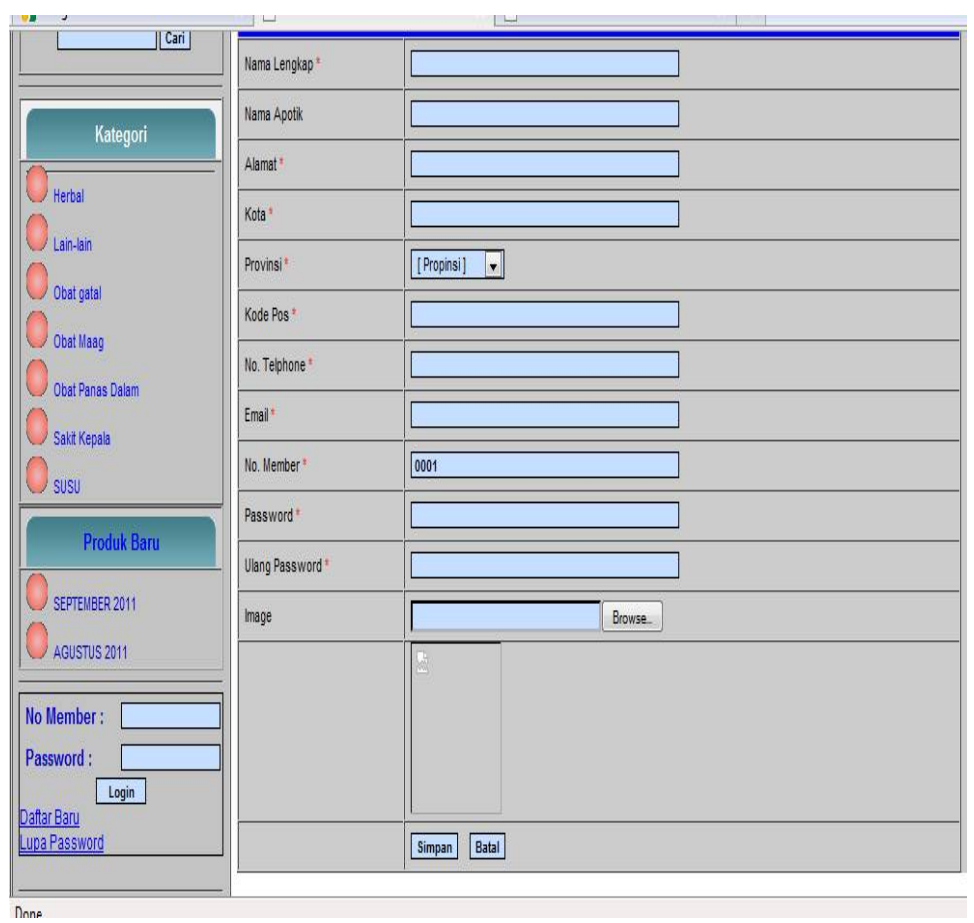

Gambar 11 Pendaftaran pelanggan

ELKOM Vol. 11, No. 2, Desember 2018: 1-15 
11

Keterangan :

Gambar diatas menunjukkan halaman form untuk pendaftaran sebagai pelanggan baru. Seseorang dapat mengisi form tersebut untuk menjadi member perusahaan. Jika sudah terdaftar pelanggan dapat memesan barang dari website tersebut.

9. Aktivasi akun

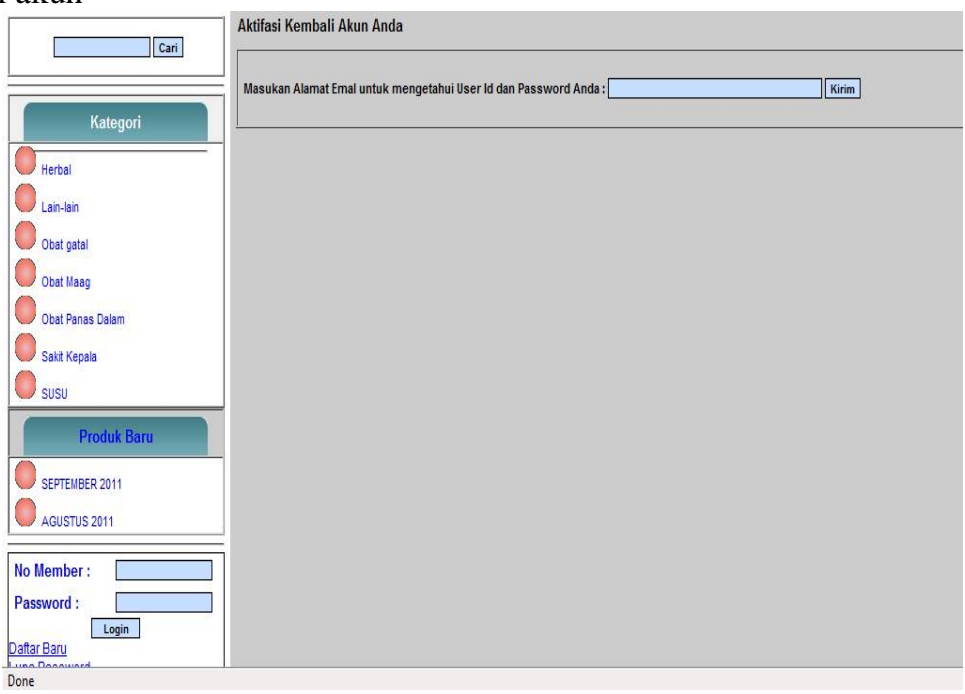

Gambar 12 Form Halaman Aktifasi Akun

Keterangan :

Gambar diatas menunjukkan form halaman aktifasi akun jika Pelanggan lupadengan user id dan password, pelanggan

bisa menanyakan user id dan password dengan cara mengklik tombol lupa password. Kemudian harus memasukan alamat email untuk mengetahui user id dan password.

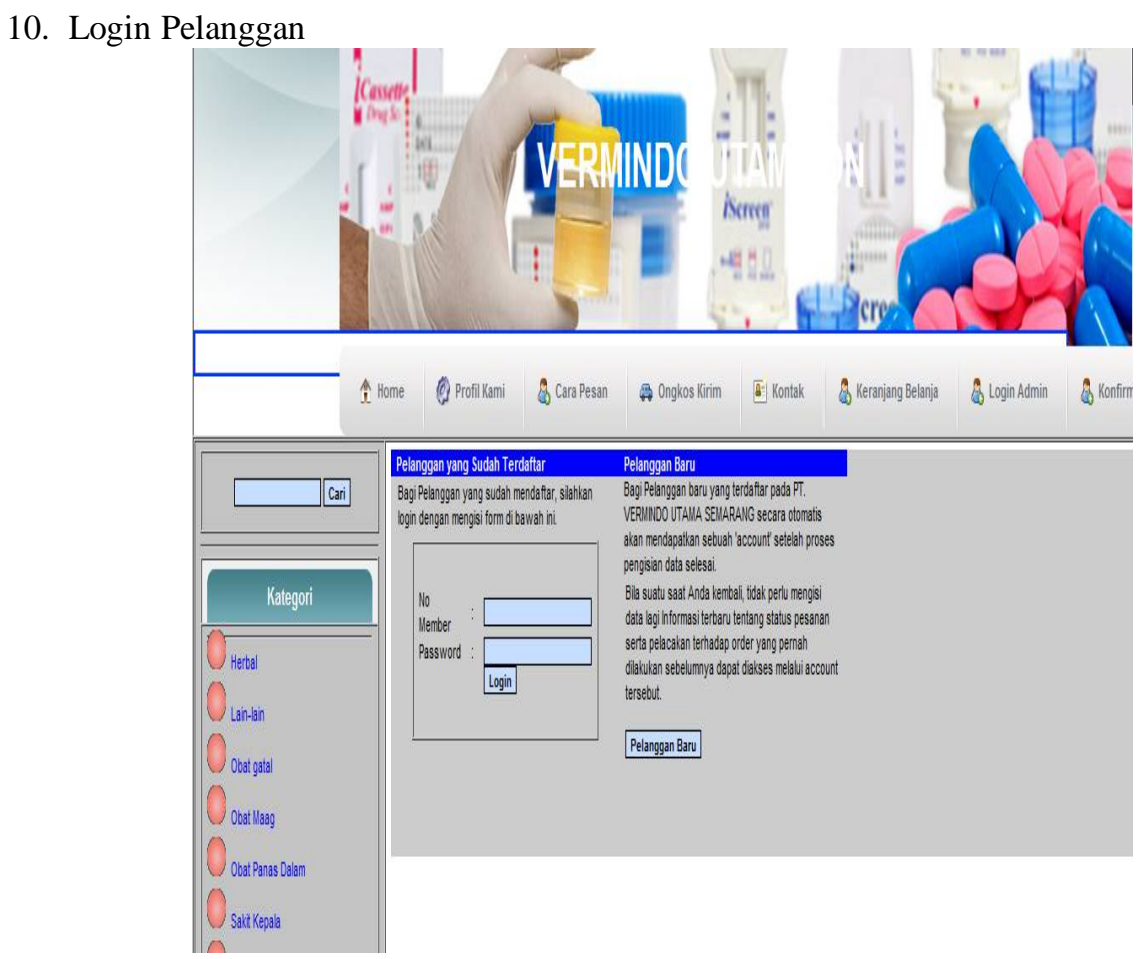

Gambar 13 Login Pelanggan 
Keterangan :

Gambar diatas menunjukkan form halaman login pelanggan untuk dapat melakukan pemesanan barang. Pelanggan harus memasukkan no member dan password dengan benar agar dapat melakukan pembelian.

11. Kritik Saran

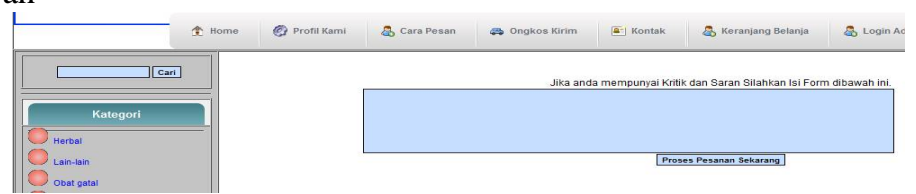

Gambar 14 Kritik dan saran

Keterangan :

Gambar diatas menunjukkan form halaman kritik dan saran sebelum proses pemesanan.

12. Pesanan dan Jumlan Bayar

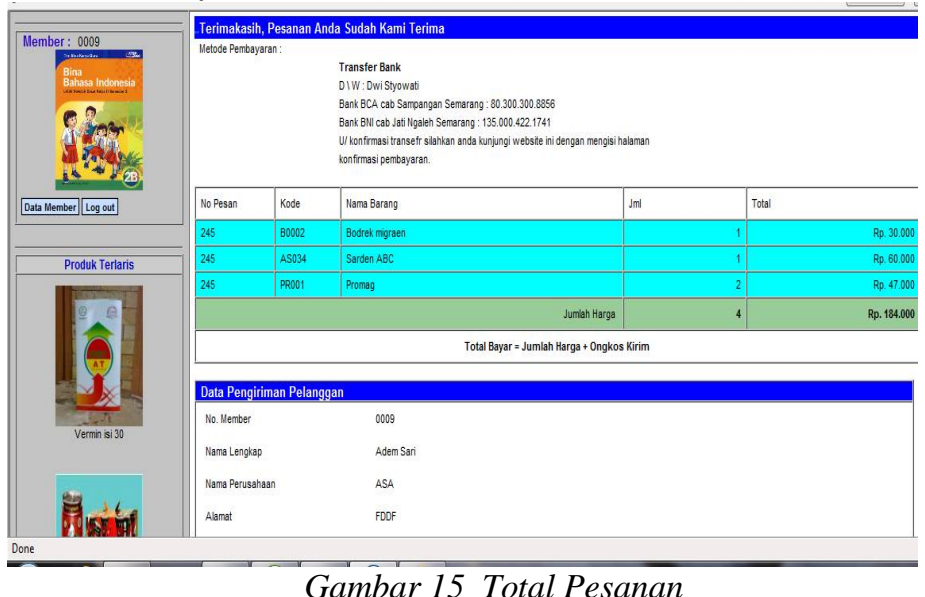

Gambar 15 Total Pesanan

Keterangan :

Gambar diatas menunjukan halaman jumlah barang yang dibeli dan total harga yang harus dibayar. Harga tersebut belum termasuk ongkos kirim.

13. Konfirmasi Pembayaran

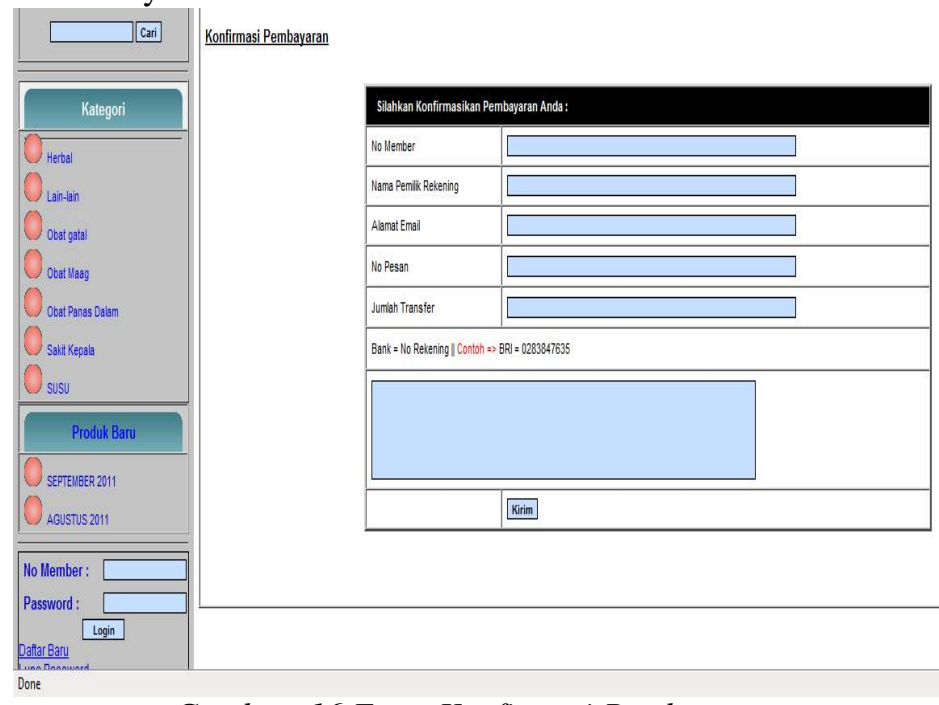

Gambar 16 Form Konfirmasi Pembayaran

Keterangan :

ELKOM Vol. 11, No. 2, Desember 2018: 1-15 
Gambar diatas merupakan halaman konfirmasi pembayaran. Setelah pelangga melakukan transfer uang ke rekening PT. Vermindo Utama Semarang langkah selanjutnya pelanggan melakukan konfirmasi pembauaran dengan mengisi form diatas.

\section{Login Admin}

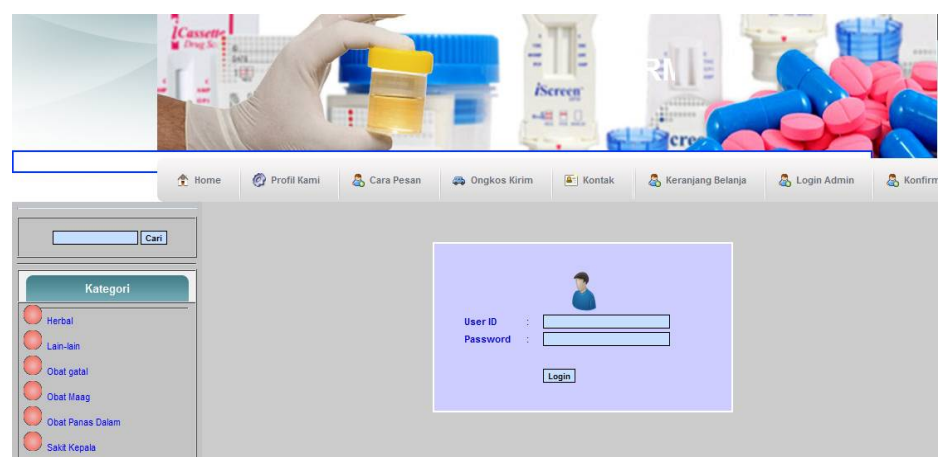

Gambar 17 Form Login

Keterangan :

Gambar diatas menunjukkan halaman login administrator. Admin harus memasukkan user dan password dengan benar agar dapat masuk ke halaman administrator.

15. Selamat User

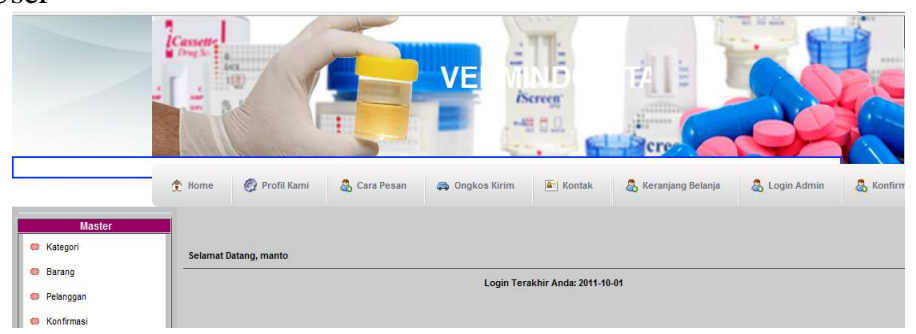

Gambar 18 Login Sukses

Keterangan :

Gambar diatas menunjukkan administrator sukses melakukan reistrasi. Selanjutnya dapat mengakses administrator.

16. Form Kategori

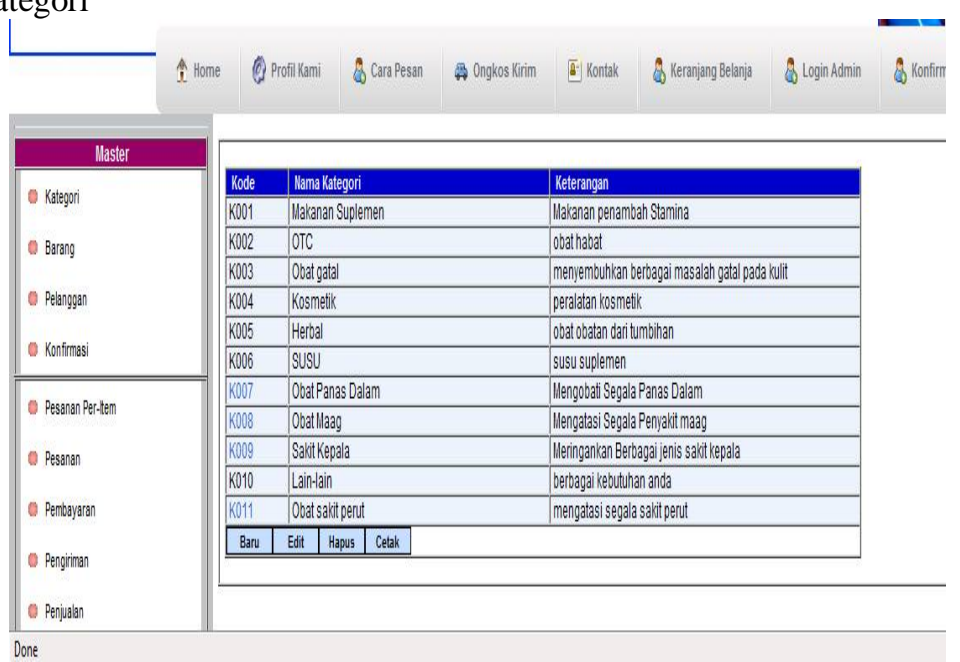

Gambar 19 Form Kategori 
Keterangan :

Gambar diatas menunjukkan form dari kategori barang. Administratro dapat menginput data kategori, edit kategori, hapus kategori, batal input, dan mencetak data kategori.

17. Laporan barang

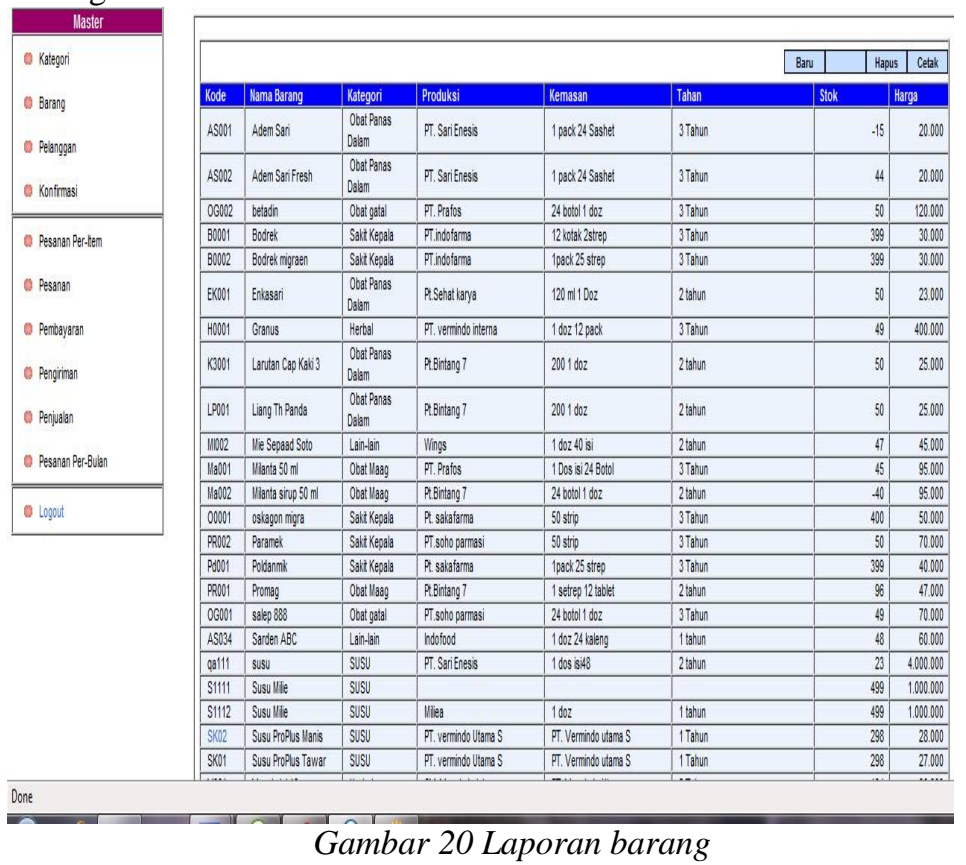

Keterangan :

Gambar diatas menunjukkan halaman laporan data barang. Admin sekaligus dapat menambah barang, edit barang, hapus barang, dan mencetak data barang.

\section{Kesimpulan}

Dari hasil penelitian dan pengamatan yang dilakukan di PT. Vermindo Utama Semarang terhadap sistem yang berjalan, maka penulis dapat mengambil kesimpulan sebagai berikut :

1. Kendala yang dihadapi PT. Vermindo Utama Semarang yaitu kesulitan dalam mengembangkan pemasaran terhadap produk-produk yang telah dihasilkan oleh perusahaan PT. Vermindo Internasional Semarang. Oleh karena itu, perlu diadakan pengembangan sistem untuk meningkatkan penjualan PT. Vermindo Utama Semarang dengan cara membangun sebuah web yang nantinya akan mempermudah Pelanggan dalam melakukan pemesanan.

2. Informasi yang dihasilkan dari sistem pemesanan yang baru adalah sebagai berikut :

a. Sistem informasi pemesanan barang berbasis web dapat digunakan sebagai media promosi dan informasi produk yang dimiliki PT. Vermindo Utama Semarang ke pelanggan terutama jika ada produk baru.

b. Membantu mempermudah pelanggan dalam melakukan pemesanan

c. Mempercepat pemesanan dan mengurangi keterlembatan dalam pengiriman barang yang dipesan.

Sebagai media promosi yang sekaligus dapat digunakan sebagai media pemesanan dengan mudah tanpa dibatasi jarak dan waktu.

\section{Daftar Pustaka}

Abdul kadir, 2006; " Desain aplikasi web dengan Macromedia MX”, C.V Andi Offset, Yogyakarta. Didik Dwi Prasetyo, 2008; "PHP dan MySQL untuk membuat Ecommerce", Gramedia, Jakarta.

Drs. H. Syamsury, Apt, 2006; ” Dasar dan hitungan farmasi”, Penerbit Buku Kedokteran, ECG.

Hartono, Jogiyanto, 2005, Pengenalan Komputer, Penerbit Andi Offset, Yogyakarta.

ELKOM Vol. 11, No. 2, Desember 2018: 1-15 
Jogiyanto, HM. 2005, Analisa Desain Sistem Informasi : Pendekatan Terstruktur Teori dan Praktek Aplikasi Bisnis, Edisi Ketiga, Cetakan Kedua, Andi Offest, Yogyakarta

Juju Dominikus, M Sykrie 2009; " Aplikasi Web dengan PHP + database Mysql”, Andi Offset, Yokyakarta.

Musyawarah, Rina. 2005, Membangun Apilikasi Database Berbasis Web Untuk Pemula, PT. Elex Media Komputindo, Jakarta

Pramono, Andi dkk, 2005, “Kolaborasi Flash, Dreamweaver”, dan PHP Untuk Aplikasi Website, Andi Offset, Yogyakarta.

Raymond Mcleod, Jr. 2008, "Sistem Informasi Manajemen edisi” 10, Salemba Empat, Jakarta.

Sidik, Betha, 2006, Pemrograman WEB dengan PHP, Informatika Bandung .

Sunarto, S. Kom, 2009; ”Teknologi Informasi dan Komunikasi”, Grasindo, Jakarta.

Suparjati dkk, 2006; ” Administrasi Perkantoran Tata usaha dan kearsipan”, Kansius, Yogyakarta.

Sutarman, 2008; “Membuat aplikasi web dengan PHP dan MySQL”,Graha Ilmu,Yogyakarta

Suyanto, A.H, 2006, Web design theory and practices, Andi Offset, Yogyakarta.

Yunirman Rijan, 2009; " Cara mudah membuat surat perjanjian/kontrak dan surat lainnya", Raih Asa Sukses, Bogor.

Yuhefizar, Y, 2008; “Pemrograman Web dan PHP”, PT. Elex Media Komputindo, Jakarta.

Yusuf Haryono, 2008, Dasar-dasar Akuntansi, Andi Offset, Yogyakarta 